\title{
Guide and Position of the International Society of Nutrigenetics/Nutrigenomics on Personalized Nutrition: Part 2 - Ethics, Challenges and Endeavors of Precision Nutrition
}

\author{
Martin Kohlmeier ${ }^{a} \quad$ Raffaele De Caterina $^{b} \quad$ Lynnette R. Ferguson $^{c}$ \\ Ulf Görman $^{d}$ Hooman Allayee $^{e}$ Chandan Prasad $^{f}$ Jing X. Kang ${ }^{g}$ \\ Carolina Ferreira Nicoletti ${ }^{\text {h }}$ J. Alfredo Martinez ${ }^{i, j}$ \\ ${ }^{a}$ Department of Nutrition, School of Public Health, School of Medicine, University of North \\ Carolina at Chapel Hill, Chapel Hill, N.C., USA; ' Institute of Cardiology 'G. d'Annunzio' University \\ and Center of Excellence on Aging, Chieti, Italy; ${ }^{C}$ Discipline of Nutrition, and Auckland Cancer \\ Society Research Centre, FM \& HS, University of Auckland, and Nutrigenomics New Zealand, \\ University of Auckland, Auckland, New Zealand; ${ }^{d}$ Ethics Unit, Centre for Theology and Religious \\ Studies, Lund University, Lund, Sweden; e Department of Preventive Medicine, USC Keck School \\ of Medicine, Los Angeles, Calif., f'Department of Nutrition and Food Sciences, Texas Woman's \\ University, Denton, Tex., and 9 Laboratory for Lipid Medicine and Technology, Department of \\ Medicine, Massachusetts General Hospital and Harvard Medical School, Boston, Mass., USA; \\ ${ }^{h}$ Department of Internal Medicine, Faculty of Medicine of Ribeirão Preto, University of São \\ Paulo, Ribeirão Preto, Brazil; i'Department of Nutrition, Food Science and Physiology, and \\ Center for Nutrition Research, University of Navarra, and Navarra Institute for Health Research \\ (IdiSNA), Pamplona, jCIBERobn, Physiopathology of Obesity, Carlos III Institute, Madrid, Spain
}

\section{Key Words}

Nutrigenetics · Nutrigenomics · Nutriomics · Genetic tests · Functional foods · Personalized nutrition · Omics · Public health

\begin{abstract}
Nutrigenetics considers the influence of individual genetic variation on differences in response to dietary components, nutrient requirements and predisposition to disease. Nutrigenomics involves the study of interactions between the genome and diet, including how nutrients affect the transcription and translation process plus subsequent proteomic and metabolomic changes, and also differences in response to dietary factors based on the individual genetic makeup. Personalized characteristics such as age, gender, physical activity, physiological state and social status, and special conditions such as pregnancy and risk of disease can inform di-
\end{abstract}

This paper was presented at the 10th Congress of the International Society of Nutrigenetics/Nutrigenomics (ISNN), Tel Aviv, Israel, May 22-26, 2016. 
etary advice that more closely meets individual needs. Precision nutrition has a promising future in treating the individual according to their phenotype and genetic characteristics, aimed at both the treatment and prevention of disease. However, many aspects are still in progress and remain as challenges for the future of nutrition. The integration of the human genotype and microbiome needs to be better understood. Further advances in data interpretation tools are also necessary, so that information obtained through newer tests and technologies can be properly transferred to consumers. Indeed, precision nutrition will integrate genetic data with phenotypical, social, cultural and personal preferences and lifestyles matters to provide a more individual nutrition, but considering public health perspectives, where ethical, legal and policy aspects need to be defined and implemented.

(c) 2016 S. Karger AG, Basel

\section{Introduction}

Recognition of diverse individual nutritional needs and responses to diet are changing standards of nutritional care, creating new possibilities for personalization [1]. In the following, the term nutrigenetics will refer to interactions of inherited DNA sequence variants with individual nutrients, while the term nutrigenomics, in the narrow sense, will refer to nutrition-related DNA modifications and to regulatory interactions of nutrients and bioactive food components with DNA and RNA elements [2].

Thus, nutrigenetics considers the influence of individual genetic variation on differences in response to dietary components, nutrient requirements and predisposition to disease [3]. Not all single-nucleotide polymorphisms (SNPs), however, influence gene transcription and the protein structure [4] because some changes in nitrogenous bases will not be reflected in an amino acid change leading to protein expression. On the other hand, broadly speaking, nutrigenomics includes the study of interactions between the genome and diet, including how nutrients affect the transcription and translation process plus subsequent proteomic and metabolomic changes, and also differences in response to dietary factors based on individual genetic makeup [5].

Characteristics such as age, gender, physical activity, physiological state and social status, and special conditions such as pregnancy and risk of disease [6] can inform dietary advice that more closely meets individual needs [7]. In this context, the USDA indicated published new population nutrition guidelines in 2016, where the individual nutrition to meet personalized cultural and traditional preferences is included in the new recommendations [8]. Nutrigenetics and nutrigenomics would be ideal tools for informing such guidelines on personalized nutrient intake.

Current views on personalized nutrition encompass omics technologies, functional foods, genetic products, future endeavors and achievements, particularly those relating to legal and ethical aspects, application in clinical practice, and consumer scopes in terms of guidelines, commercialization and epidemiological factors. Technologies such as next-generation sequencing platforms (arrays, bead chips and sequencing approaches) provide a rapid scan of known SNPs and CNVs in the genome to show DNA variations in individuals as well as gene expression changes $[9,10]$. This paper aims to address endeavors and achievements made and to foresee likely progress and challenges in the field of precision nutrition.

Precision nutrition 4.0 involves Big Data management and ethic foresight analysis for the convergence of agrigenomics, nutrigenomics, nutriproteomics and nutrimetabolomics [11]. Indeed, precision nutrition requires the use of genomic information but also phenotypical, cultural, behavioral and lifestyle preferences for health maintenance and disease management to guide universal and personal advice [12]. 
Kohlmeier et al.: Guide and Position of the ISNN on Personalized Nutrition: Part 2 Ethics, Challenges and Endeavors of Precision Nutrition

\section{Genetic Tests for Personalized Nutrition}

In order to offer individual dietary prescriptions, it is necessary to analyze the molecular mechanisms and systems interacting in human health [13]. Uses of molecular biology technologies include detection of SNPs and identification of candidate genes and polymorphisms putatively involved in gene-nutrient interactions, both of which may dictate dietary recommendations based on genotype [14]. Genetic test panels have emerged that identify genetic variance (risk alleles), which may be a key to understanding metabolic diseases and their associated therapies. This genetic information, combined with anthropometric, biochemical and dietary assessments, will greatly enhance the ability of health professionals to recommend a personalized/individualized diet.

There are two types of genetic tests: in vitro diagnostic tests and laboratory-developed tests (LDTs). In vitro tests are produced to be distributed and used by many laboratories; the LDTs are used exclusively by the test developer's laboratory [15]. Direct-to-consumer (DTC) genetic tests are designed by different companies, and their classification is not yet established $[15,16]$. The demand for DTC genetic tests has increased to the point where they are currently the main tool for genetic screening in personalized nutrition [16], primarily because they facilitate direct access to an individual's genetic information [17]. Such information helps predict predisposition to future health problems, thus representing a promising preventive tool. Similarly, genetic information can indicate which individuals may benefit from specific dietary interventions. Hence, dietary recommendations based on genotype offer a more effective tool for improving public health [18]. The Human Genome Project has opened up the possibility of a new approach to customized diets that can help mitigate the prevalence of obesity and other chronic diseases [19]. One such example is familial hypercholesterolemia, a genetic disease in which personalized nutritional advice would be useful [20].

The greatest challenge for any dietary treatment is that of motivating individuals to change their dietary habits and behaviors. Similarly, the success of personalized diets is dependent on an individual's motivation and on prospective benefits offered by such dietary changes [21]. Eating is a process that involves psychosocial factors, and therefore, individualization of diet based only on genetic information can generate ethical and operational controversies. Nevertheless, health professionals routinely evaluate a range of biological data such as height, weight and gender, and biomarkers like cholesterol or vitamin status when formulating personalized diets. Nutrigenomics has now provided sufficient value that genotype should also be included. There is evidence that nutrigenomic advice is better understood and more likely to be followed compared with general dietary advice [17, 22]. Among numerous other advantages, nutrigenomics is proven to be beneficial in long-term weight control [23], which has been checked within the Food4me project.

Those individuals who are identified as having a higher disease risk through a genetic test may be more motivated to follow dietetic recommendations [24]. This fact helps address widespread issues associated with changing eating behaviors, including dietary changes based on genetics. Given that food consumption is a complex area that involves emotional and pleasure-based responses, a multitude of factors must be considered when working with an individual's motivation to follow dietary recommendations. In this context, Food4me approaches the broader, more complex aspects of food consumption and production in a number of ways; these include evaluating the efficacy of personalized nutrition in changing behavior and in adherence to advice, and business implications, consumer needs and perceptions, and ethical aspects of personalized nutrition in Europe [25]. 
Kohlmeier et al.: Guide and Position of the ISNN on Personalized Nutrition: Part 2 Ethics, Challenges and Endeavors of Precision Nutrition

\section{Functional Foods in Personalized Nutrition}

Food choices are based primarily on individual preferences, including sensory likes, availability and cultural habits [26]. New tools are needed to support personalized nutrition that recognize consumer demands, define new biomarkers and translate such issues to the nutritional market [27] in order for this approach to be useful to individuals. Furthermore, a collaborative effort between the food industry and culinary practice is necessary [28] in order to create a nutritional landscape of personalized nutrition, where the food and pharmaceutical industries develop new products and services according to specific groups and needs, including the genetic makeup of the consumer [27, 29].

Functional foods can be defined as foods designed to increase the levels of palatability and nutrient bioavailability, beneficially affecting the body, improving health status and reducing the risk of disease [30]. Personalized nutrition is promoting development of functional foods aimed at improvement of health status [31]. To match this development, the food industry needs to create new food production technologies to meet new demands.

New technologies play a rapidly increasing role in supporting an individual's food/diet preferences. Use of electronic devices such as the Internet and cell phone applications has become more common. In recent years, companies have used the Internet to offer personalized nutrition services based on DNA analysis of the individual [32].

One such example is the Internet support tool called Personal Online Nutrition Guidance (PONG), in which daily menus can be planned according to individual nutritional preferences, using genetic information to establish individual goals [33, 34]. The Technology Assisted Dietary Assessment (TADA) project [35] provides a mobile phone application (Mobile Phone Food Record) to assist in the assessment of dietary intake [36], which provides personal nutritional recommendations to individuals based on their nutrient intake [37].

Central to the current demand for new communication tools, online services and applications is the question as to whether the easiest choice is the healthiest choice. Frequent use of such tools means lesser reliance on the advice of health professionals. This raises the question as to whether making changes to an individual's diet based on advice from programs and applications is the best option.

A particular concern in analyzing diet using online and 'app' advice is the efficacy or lack thereof in such tools. Recent studies have evaluated the role of a single nutrient in metabolism and genomics pathways; however, an individual eats a whole diet that contains a large number of different nutrients. This fact indicates the importance of assessing dietary patterns rather than single nutrients acting in isolation because observing such combinations of nutrients is likely to be more useful. Hence, cluster analysis can be used to study food groups and dietary patterns that could be associated with genetic analyses.

Many new questions are emerging that relate to the creation and marketing of new food products. These include scientific verification in support of such products, whether everyone should choose a healthy diet or just those with a genetic predisposition to particular diseases, and how new products will reach the right people [38].

\section{Applications in Public Health: Population-Based Advice versus Personalized Advice}

Public health nutrition interventions aim to develop strategies that promote good health through diet [39] and to cover the nutritional needs of most of the population. Nutritional epidemiology studies mainly focus on evaluating the role of diet and nutrients in disease prevention to assist with population health guidelines [40] and reduce the prevalence of 
disease. These studies are important because they can assess dietary aspects as well as the phenotype and genotype. However, the methods of data collection and food intake evaluation concurrent with genetic evaluations are currently limited, hence affecting the accuracy of these methods $[41,42]$.

Nutritional interventions at the public health level utilize dietary guidelines for the population, as well as informing individual recommendations in clinical nutrition; however, such advice is based on population studies [42]. Advances in human genetic studies and in omics technologies are contributing to the modification and improvements of this framework, but the use of genetic tools in public health nutrition policy is not prevalent. [43]. Application of genetic knowledge in public health interventions is a crucial issue. For instance, if scientists know that a polymorphism can modify the requirement for a nutrient, or of a situation in which a polymorphism increases the risk of diabetes in individuals with a low fiber intake, the question arises as to whether such information can be translated to all populations.

Individualized nutritional recommendations also bring their own issues, such as the difficulty of making simple, general recommendations; the advice to eat five servings of fruits or vegetables per day is one such example [33]. A further issue is the increased complexity of an individual's food choices when gene-nutrient interactions are taken into account.

The genetic variants that affect nutritional metabolism and requirements can be detected both through candidate gene methods and through whole genomics analyses. The candidate gene method evaluates associations between genetic polymorphisms and the resultant effects in metabolic pathways [44]. One example of an SNP affecting nutrient requirements is the MTHFRAla222Val (C>T) polymorphism that impacts on folate metabolism [45]. Individuals who have the mutant allele T in homozygosis (TT) need a greater folate intake to lower their risk of folate-related diseases. Therefore, carriers of this polymorphism may need specific folate supplementation rather than those values recommended by RDAs, given that such guidelines currently cover both wild and mutant genotypes. Folate intakes for those carrying this SNP should be higher, particularly for TT individuals [46]. To give another such example, those who have Down syndrome (trisomy 21) have increased zinc and folate requirements [47]. The activation of the three chromosomes results in an overexpression of cystathionine$\beta$-synthase, an important gene in folate metabolism $[47,48]$.

Long-chain omega-3 polyunsaturated fatty acids (PUFAs) are a further example of the fact that 'one size fits all' cannot be applied in nutritional advice. Those individuals who carry the A allele for the APOA1 polymorphism (G>A) show an increase in HDL cholesterol levels after increased consumption of PUFAs, while those with the GG genotype show a reduction in these levels [49]. Similarly, individuals with major risk alleles for serum- and glucocorticoidinducible kinase 1 (SGK1) display higher systolic blood pressure when on a high-salt diet [50].

SNPs and other genetic variants can also be associated with specific ethnic groups [51, 52]. For example, celiac disease, which is characterized by gluten intolerance, affects $2.4 \%$ of adults in Finland, $0.3 \%$ in Germany and $0.7 \%$ in Italy [53]. In European populations, the frequency of the mutant allele of Apo E4 is higher in northern countries than in southern countries [54]. The hereditary persistence of lactase is common in individuals from northern Europe (90\%), occurs in 50\% of subjects in the Middle East and Mediterranean, but affects less than $20 \%$ of African individuals [55, 56].

Dietary requirements suitable for one genotype are unlikely to be appropriate for individuals with a different genotype [33]. Some researchers believe that the solution is to find common levels of consumption that would work for most genotypes. However, this approach is limited by the fact that recommendations still need to differ for those who have a variant that increases particular requirements and those who do not. Another approach is to categorize individuals into subgroups with similar genetic characteristics. These subgroups may differ in the activity of transport proteins and/or enzymes that require particular micronu- 
trients as a cofactor [57]. Optimal dietary recommendations should be based on assessments of bioavailability, bioactivity and bioefficacy of nutrients [13], and must be individualized according to genotype in order to reduce disease risk and to increase health [58].

Dietary reference intake (DRI) recommendations need to be informed by emerging knowledge of genetic diversity in individual metabolism and requirements [33]. A natural result of this will be that DRIs offer recommendations towards population groups in which the frequency of specific alleles is high.

A better targeted public health intervention is the main aim of most nutrigenomics studies [59]. Knowledge of genetic and molecular profiles of populations should not only benefit control and reduction of disease prevalence, but should also contribute to prevention strategies. In this context, the knowledge that nutrigenomics offers is likely to affect the food industry, in particular the design and manufacture of products, including fortified foods. It is hoped that nutrigenomics will also assist in creating new nutritional policies for diverse populations, with disease prevention programs being implemented only for those who show evidence of disease risk. Similarly, nutritional supplementation policies would be more effective if adequate clinical trials showed who the supplements would be most applicable for. Once people understand how useful such policies can be to them as individuals, greater adherence is expected to be achieved [60].

\section{Ethical, Legal and Social Aspects in Nutrigenetics}

The use of a genetic profile in nutritional advice raises ethical, legal and social issues [33], including use of genetic tests, nutrigenetics research and clinical practice [61], collection and storage of samples, children's involvement, and information passed on to the family [62].

\section{Consumer Acceptance and Adherence}

Public acceptance of new technology is clearly influenced by recipients' estimation of benefits and costs or risks involved. In many cases, there is also a component of moral beliefs and attitudes [63,64]. There is good public acceptance of genetic testing for hereditary diseases [21]. Several studies indicate that there is also a widespread positive attitude among the public toward using genetic tests for personalized nutrition [65-67]. Socioculturally disadvantaged groups seem to interpret genetic testing positively [68]. Individual reactions to innovations in food appear to be associated with conceptions of health benefits, including a lowered risk of disease [69].

There is limited evidence, however, that genotype-based dietary advice will motivate appropriate behavior changes. A study which compared the effect of knowledge of genetic profile on the nutritional behavior of individuals indicated that while most participants liked the specific recommendations, those who received detailed information by genotype were more likely to respond than those who received standard recommendations [70]. Another study showed that individuals believe that health professionals provide better information on genetic profile than DTC genetic tests [18]. Other authors found no changes in diet, exercise or psychological behavior in a genetic test follow-up, concluding that use of DTC genetic tests is controversial [71]. It should be noted, however, that this study may lack current relevance, given that it employed a genetic test that has not been continued.

\section{Consumer Protection}

Much attention has been given to informed consent as a tool for protection of individuals involved in health- and research-related interventions, including access to sensitive information and undertaking of burdensome or risky activities. When it comes to genetic infor- 
mation, this discussion has partly focused on the question as to whether genetic information is inherently of a special kind or not compared to general health information. Regardless of this aspect, it is crucial to handle genetic information with care because such information is sensitive, may have far-reaching implications and can easily be misused. Because of such considerations, a number of authorities have worked toward making informed consent a prerequisite for performing genetic tests. Persons undergoing tests must know the benefits and risks of genetic testing, and must also be aware that changes to dietary and other lifestyle factors may be suggested based on the results of such tests [33]. For instance, in Europe the treaty on genetic testing for health purposes states that genetic probes may only be carried out under quality control, individual supervision, and after informed consent [72]. However, informed consent is often perceived as a formality of limited significance, and a number of additional efforts need to be considered in order to achieve adequate consumer protection.

Quality of genetic tests and subsequent nutritional or lifestyle advice is of crucial importance. Currently, there are approximately two million test panels commercially available [73]. These genetic tests are heterogeneous in relation to polymorphisms analyzed, and some laboratories may use an erroneous database, promoting false results. Some studies are performed in a specific population and cannot be extrapolated to other ethnic groups. Genetic tests by Spanish and American laboratories of genes found in GWAS studies were summarized by SanCristobal et al. [20]. The authors noted, however, that some genetic polymorphisms evaluated in genetic panels were never reported in scientific studies. In addition, some studies have been performed in a small population, and the results need to be validated with a larger number of people before being applied in commercial tests [20]. Dietary recommendations based on inconclusive or unreliable information may result in unnecessary limitations and concerns [38]. Important questions include: 'does the test detect just the genotype or more when providing the DNA sequence?' and 'how can this information be used?' Understanding and reporting are an important part of the genetic test process. Identification of genetic variants that may predispose individuals to chronic disease is not well established and may therefore pose a significant barrier to nutrigenomics-based personalized nutrition [62]. For clinical application of genetic knowledge, a health professional needs to know how to interpret genetic and molecular tests and to extract the necessary information for planning dietary interventions [76]. Because of this, genetic nutritional education is needed for health professionals at the forefront of advances in nutrigenomics [74]. Further, it is urgent that courses in nutritional genetics are included in the university curriculum $[75,76]$ in order to educate and orientate a new generation of professionals, the nutrigenomicists [74].

Several ethical questions concern privacy of information. Genetic profiling, including prediction of future health events, may interest insurance companies, possible or actual employers, and others such as schools or athletic teams [77]. Consequently, a person may be asked to take such genetic tests or to reveal the results of tests already undertaken. This raises the risk of discrimination, despite recommendations that genetic profile should be considered confidential [78].

Another question arises out of the fact that we share many of our genes with family members. Should we thus share personal genetic information with them? How should parents act in relation to their children? Should health professionals involve family members? Family history is an important tool to determine the risk of hereditable diseases and may help in the use of genetic testing to predict future disease [61]. While genetic tests help to make individuals better informed [79], if the subject has direct access to genetic testing, they may misinterpret the results.

In addition, the spectrum of genes tested can give a person more information than they ask for, and may contain unwanted results which can cause anxiety [80]. For this reason, 
health professionals must address the ethical questions connected to opportunistic screening, i.e. ad hoc tests offered by a medical doctor to a patient without symptoms or a test made upon request from an individual patient without symptoms or known risk factors [38]. There is currently no consensus on opportunistic screening among health professionals because although a particular test may not seem necessary, individuals may claim the right to ask for available services [81].

\section{Guidelines and Legal Regulations}

Guidelines for the regulation of genetic tests and analyses aim to protect individuals from harmful services and include analytical regulations (measure of the accuracy of genetic tests to identify genes and polymorphisms), clinical validity (assess the accuracy of interpretation and association with clinical status) and clinical utility (evaluate the possibility of reaching a desired clinical result with a recommended intervention) as factors of consideration [82, 83]. In 2007, the European Nutrigenomics Organization (NuGO) developed guidelines for nutrigenomic research [84].

Any country or national regulatory agency can establish legislation for clinical genetics [85]. Producers of genetic testing have specific responsibilities according to prevailing ethical/legal rules in their own country. However, legal regulation remains insufficient, with genetic test guidelines still in development in many countries. Progress is, however, being made, with many government agencies and organizations having published information and guidelines regarding DTC to help clarify, inform and alert individuals [86-89].

The USA Supreme Court made a landmark decision in 2013, when it determined that DNA in its natural form cannot be patented [90]. This decision [90] helped facilitate the integration of genomics and clinical practice, resulting in laboratories having the freedom to create new products for the benefit of the population [91]. The Medicine and Healthcare Products Agency (MHPA) pointed out that nutrigenomics tests are like 'lifestyle tests' (not clinical testing with the intention to provide dietary advice) and would not have to follow a legislation [83, 87]. However, the Human Genetic Commission disagreed with this position and proposed that 'lifestyle tests' should be considered in the same way as in vitro diagnostic tests and should, therefore, follow legislation [83]. Currently, three federal agencies are involved in regulating genetic tests in the USA: the Food and Drug Administration (FDA), the Centers for Medicare \& Medicaid Services (CMS), and the Federal Trade Commission (FTC) [92]. The FDA has the broadest authority, under the Federal Food, Drug and Cosmetic Act, and exercises this authority depending on how a test comes to market. If a test is sold to multiple laboratories as a kit (a group of reagents used in processing of genetic samples that are packaged together) the FDA regulates the test. To date, these have comprised a comparatively small number of tests. If, as more commonly happens, a test comes to the market as an LDT, developed and carried out by a single laboratory, the FDA does not currently regulate such a test. Despite the FDA announcing in 2010 that it plans to regulate LDTs, and notice given to Congress by the FDA on July 31,2014, that it would be announcing draft guidelines on the regulation of LDTs in the next 60 days [92], no further announcement has been forthcoming at this time. This situation has prompted much discussion and concern in the scientific community that proposed regulation will impact on researchers in academic laboratories developing and offering timely testing [93]. The CMS regulates all clinical laboratories performing genetic testing, ensuring their compliance with the Clinical Laboratory Improvement Amendments (CLIA) of 1988. However, rather than examining whether genetic tests performed are clinically meaningful, the CLIA focuses only on qualifications of technicians, quality control of lab processes and proficiency of testing. The FTC's mandate is limited to the ways in which tests are advertised and ensuring that information is not false or misleading. 
In 2002, the EU published a paper on the regulation of genetic tests that addresses patients' rights in many European countries, principally regarding the right to information, confidentiality, privacy and informed consent [78]. The UK's Human Genetics Commission (HGC) issued a document in 2010 with principles relating to genetic tests that included transparency, accessibility and ease of information; it also recommended standardized testing techniques [87]. In 2009, the German government implemented rules related to accreditation of laboratories, the need for informed consent and genetic counselling [94]. In Belgium, there is no specific legislation for DTC tests; however, there is a law stating that if a DTC test is of a medical nature, a medical physician must be involved [95]. The Netherlands as a country also has no specific regulation; however, some genetic tests are required to carry a permit issued by the Dutch Minister of Welfare and Sports [96]. In a recent summary of the regulatory framework in Europe, Food4Me concludes that neither the EU nor its Member States have legal instruments specifically dealing with personalized nutrition. Instead, due to its new and special characteristics, personalized nutrition falls within the ambit of several legal instruments. Hence, it becomes unclear which legal instruments may apply to any specific personalized nutrition offering [97].

The Department of Health of the Australian Government determined that testing should ensure safety and quality, and prohibits the sale of DTC testing for serious diseases [98]. In Latin America, most countries do not have any specific rules for genetic tests.

\section{Commercialization}

Use of DTC genetic tests has generated controversy, with online companies offering tests being subjected to strong criticism for misleading consumers as well as for the imbalance between far-reaching promises and contrasting disclaimers [67]. This has led to discussions about the damage that such tests may cause consumers, as well as possible threats to individual autonomy [99]. In this context, 23 andMe Inc. is a company which formerly sold a DTC genetic test via online platforms able to detect genetic variants associated with more than 254 specific diseases and conditions, without health professional involvement. In a warning letter dated November 22, 2013, the US FDA ordered 23andMe to discontinue the marketing of their Personal Genome Service, because it did not comply with regulatory requirements regarding safety and effectiveness or possess the required marketing authorization [99101]. In response to this, for the next 2 years 23 andMe still sold genetic tests, but they no longer offered personalized advice related to results. On October 21, 2015, 23andMe issued a press release stating that they are now the first and only company to receive FDA authorization to market a DTC genetic test. The name of the approved test is the Personal Genome Service (PGS); it includes carrier status, wellness, trait and ancestry reports. While this FDA approval marks a milestone of a kind, 23andMe are careful to state that '23andMe is not intended to diagnose any health condition. You should consult a healthcare professional before making any major lifestyle changes.' Their press release of October 2015 states that their Carrier Status tests cannot determine if someone has two copies of a genetic variant, that each test is most relevant for people of certain ethnicities, that tests are not intended to diagnose a disease or to predict risk for developing a disease in the future. Further, they state that on their own, carrier status tests are not intended to tell clients anything about the health of their fetus or their newborn child's risk of developing a particular disease later in life. Several other Internet companies offering genetics-based advice, mainly in the US, have also closed down or limited their services. As already discussed, the FDA has not yet developed specific rules for genetic testing. FDA approvals given (e.g. cystic fibrosis test and high-throughput platform) have been based on an evaluation of analytical validity [102]. Such approval may be a milestone for the regulation of all genetic tests and analyses [103, 104]. 
Kohlmeier et al.: Guide and Position of the ISNN on Personalized Nutrition: Part 2 Ethics, Challenges and Endeavors of Precision Nutrition

\section{Social Issues}

In the context of personalized nutrition, food may be understood as a tool for good health. However, food is not only nutrition; it also plays a significant role in shaping and expressing social relations, plus cultural and personal identity. Personalized nutrition needs to integrate the nutrigenetic approach with everyday cultural, emotional, ethical and sensual understandings of food. Individually tailored nutritional advice needs to reach beyond recommendations for intake levels of single nutrients and include suggestions for meals and recipes [105]. In the early days of personalized nutrition, there were strong expectations that a new generation of functional foods would acquire a significant role in the field. So far, this evolution has not been the case. Instead, the current trend in personalized nutrition, to focus recommendations on choice and intake of food already available, seems to more easily integrate the social aspects of eating.

Concerns have been expressed that personalized nutrition may trigger unhealthy quests for health, such as healthism and medicalization of diet [106]. Currently, personalized nutrition appeals largely to a limited population segment, particularly early adopters and health seekers. Despite the fact that focusing on health may be a positive action for most adopters of personalized nutrition, there may still be those who develop health issues due to their exaggerated attention on healthy lifestyle. However, experience to date does not show any indication that personalized nutrition will be a specific risk factor in this respect. Nevertheless, the rapidly growing market for and adoption of personal health monitoring equipment may change this situation. Hence, it is important that health professionals remain alert to this possibility.

\section{Current Achievements and Progress}

Existing data support the relationships between particular genetic polymorphisms and human metabolism $[107,108]$. Some SNPs directly affect metabolic pathways and may thus explain the differences between prevalence of diseases associated with diet and dietary requirements among individuals. Other SNPs related to the processes of absorption, digestion, transportation and excretion of nutrients and metabolites contribute to a greater understanding of the role of bioactive compounds [41]. Furthermore, individual SNPs related to receptors or enzymes can alter the response to a given dietary intervention [41].

Risk factors are based on statistical estimates from epidemiological studies [109]. Late diagnosis can cause patient complications in terms of developing the most appropriate treatment and beginning such treatment as soon as possible. Use of genetic tests and tools may promote a more rapid diagnosis of disease and thus enable appropriate interventions and diets to be implemented earlier and more effectively.

Many laboratory techniques useful to personalized nutrition have already been developed, including mass spectrometry, chromatography, electrophoresis, microarrays and magnetic resonance spectroscopy [110]. Advances in nutrigenetic technologies are providing scientists and health professionals with a holistic approach of considering both nutrition and metabolism, thus improving nutritional interventions and enabling customization of diet according to individual needs [111]. A noteworthy advancement that personalized nutrition offers is that of being able to identify individuals who will benefit from precise intervention strategies [112]. Omics technologies provide identification of disease risk, identification of appropriate biomarker assays (encompassing proteomics, lipidomics and metabolomics) and analyses of food bioactives and compounds, thereby promoting better understanding of human nutrition and informing the development of customized diets. 
Kohlmeier et al.: Guide and Position of the ISNN on Personalized Nutrition: Part 2 Ethics, Challenges and Endeavors of Precision Nutrition

One particular challenge to the application of personalized nutrition remains, which once met, is likely to impact the future of nutrigenomics significantly - how to establish a metagenomic view that incorporates the following: biotransformation and digestion of food and absorption of nutrients; consideration of the entire human physiology and metabolism, and both the gut microbiota and human genome, and the interactions between these genomes.

\section{New Challenges and Possibilities: What Are We Expecting?}

The main challenges of nutrigenomics and personalized nutrition encompass scientific and technological issues, security and benefits of genetic testing, development of new technologies and assessment methods, related ethical considerations, and socially related (economic, educational, lifestyle) data collection and practice [62], as summarized here.

The first step in a nutrigenetics study is evaluating dietary intake of volunteers. Despite the evolution of omics technologies and methods, the tools for assessment of food intake (24-hour food recall, diet recalls, food frequencies questionnaires) have not developed as well/fast as omics technologies and often lack reliability. In population studies, evaluation tools should reflect long-term intake, thus enabling gene-nutrient association to be more accurate. Development and improvement of tools for better quantification of food intake should be the goal of future research [113]. One group that planned to address this is the Food4Me project, as appears in the white paper generated by this consortium [98].

Genotype alone does not enable personalized nutrition to improve health [114]. Study of polymorphisms has limitations. Most nutrition-related diseases are complex, multigenic diseases, meaning that the study of the association between genes becomes very important. New technologies, which analyze the whole genome, may help the understanding of gene interactions, discovering pathways that can influence nutritional metabolism, and hence affect nutrient requirements. Single polymorphisms cannot explain complex diseases, disorders and phenotypes; hence, the era of single polymorphism studies is probably coming to an end. Genomic studies will continue to identify new associations between genetic variants and disease risk. Improvements in genetic tests and analyses must be constant to support future applications of nutrigenomics. The development of a risk map, showing all candidate or susceptibility genes for a disease, may help future genomic analysis. The SNPsnap web service is a new tool that aids analyses of SNPs, providing corresponding sets of SNPs based on the quantity of SNPs, allelic frequency and linkage disequilibrium [115].

There is a need to replace current genetic assays with those that can encompass all new molecular and bioinformatic knowledge [116]. New development tools that facilitate collection of data (such as dried blood spots replacing vein puncture) and portable electronic devices that assist in the assessment of dietary intake will facilitate future studies in large populations. Such studies will bring challenges to laboratories, research funding agencies, universities and health professionals [117].

Studies undertaken have established that genetic markers can predict disease development [34]. Alteration in gene expression and consequently in metabolic pathways results in changes in the metabolome [13]. Tools such as disease biomarkers assist with diagnostics $[118,119]$. Examples of such biomarkers include serum retinol, zinc and ferritin [13]. In addition, dysregulated insulin secretion and elevated levels of blood glucose are metabolic biomarkers of diabetes [120]; branched-chain amino acids may be early signs of diabetes and obesity [121]; blood profile proteins [122] and circulating levels of angiotensin-converting enzyme are useful tools to predict weight loss and to help improve weight loss maintenance [123]. Epigenetics studies may also result in the identification of epigenetic markers for the risk, diagnosis and prognosis of diseases [124]. 
While the use of genomic signatures for health is still limited [125], study of relevant biomarkers enables better follow-up to the evolution of disease and allows a better choice of interventions. The widespread nature of human genetic variation can still, however, generate difficulties in the interpretation of some biomarker outcomes [13]. One of the future promises of personalized nutrition is that of identifying and evaluating valid biomarkers which can then be applied in metabolic interventions $[13,120]$.

Studies assessing the human microbiome are progressing [126]. The microbiota can alter human response to dietary compounds; additionally, food-borne microbial communities can modify diet composition. Integrated study of human nutrition that encompasses biotransformation of foods, ingestion and digestion, physiology, and metabolism, is becoming increasingly necessary [127]. In this context, study of the intestinal microbial genome is emerging as a promising tool for diagnostics and interventions in personalized nutrition [127, 128]. Lipidomics, proteomics and metabolomics are sciences that are still developing; hence, encoding the paths of metabolism and food utilization to be applied as biomarkers in dietary interventions involves future challenges for personalized nutrition [129].

Nutrimetabolomics studies focus on biomarker signatures of food components, gut microbiome and molecular profile [130]. Advances in human metabolic profiling offer improved opportunities for studying food biomarkers and individuals; thanks to such advances, individuals do not always need to be fasting to be studied [131,132].

The application of nutrigenomics and nutrigenetics in particular diseases such as cardiovascular disease is still in its infancy $[133,134]$. Study of the association between genetic and environmental characteristics may help in the implementation of future strategies and interventions to prevent and reduce obesity $[12,135,136]$, cardiovascular issues [137] and other diseases. For all of these diseases, a combined approach is necessary that integrates reduced consumption of high-density foods, adoption of an active lifestyle, and customized dietary recommendations based on phenotype and genotype, with an adequate quantity and quality of macronutrients [138].

Individual nutrition is linked to social contact and implies practical and emotional benefits [139]. For some professionals, personalization of nutrition may overlap with customization, resulting in greater autonomy for the individual. The wide range of products and services available on the Internet could distance health professionals from their patients. Internet companies offer services without the direct involvement of health professionals, which can limit interpretation and understanding [7]. One study found that while customers were negative about Internet services, they were not against individualization per se [140]. Other authors have shown that computer-tailored nutrition education had benefits in individual motivation to change diet [140]. However, in ethical terms, autonomy and responsibility should be distributed according to the ability of the patient to handle them [141].

The integration of precision nutrition into routine clinical care is a growing challenge, particularly given that this tool has value only when supported by skilled health professionals who are experienced with genetics approaches to nutrition and are able to maintain close follow-up with the patient [142]. Some dietitians reported that they do not consider themselves qualified to incorporate nutrigenomics into their practice [143], while others have no interest in personalized nutrition [75]. Similarly, many physicians lack sufficient training and information in either nutrition or genetics with which to interpret data and provide reliable advice for personal nutrition. Consumers need to develop trust in the service being offered, and thus it is important that nutrigenetics or nutrigenomics service providers achieve this confidence in order to ensure successful treatment [139].

Autonomy, beneficence, no misconduct, and justice are the principles of research ethics; however, these are changing with the new scenario of nutrigenomics studies associating diet and risk of disease [38]. In the future application of nutrigenetics and nutrigenomics, more 


Journal of
Nutrigenetics
and
Nutrigenomics

Fig. 1. Existing and future personalized nutrition recommendations.

\begin{tabular}{l|l}
\hline J Nutrigenet Nutrigenomics 2016;9:28-46 \\
\hline DOI: 10.1159/000446347 & $\begin{array}{l}\text { @ 2016 S. Karger AG, Basel } \\
\text { www.karger.com/jnn }\end{array}$ \\
\hline
\end{tabular}

Kohlmeier et al:: Guide and Position of the ISNN on Personalized Nutrition: Part $2-$ Ethics, Challenges and Endeavors of Precision Nutrition

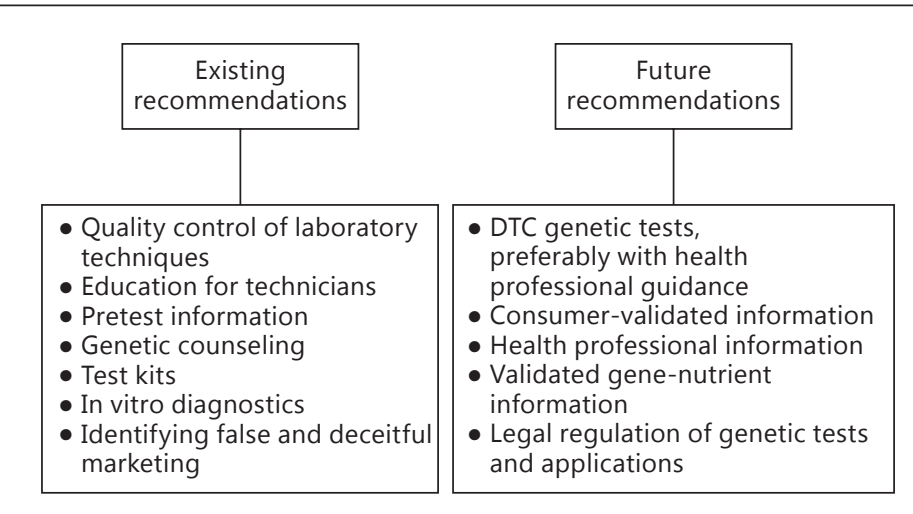

attention needs to be given to ethical issues, including cost-effectiveness and social acceptability [144]. Regulation of ethical and legal aspects of genetic testing in personalized nutrition is urgently needed; once such rules and norms are established, they may help the application of personalized nutrition [139].

According to some authors [145], studies should involve all omics technologies at various points of a longitudinal follow-up. An 'integrative personal omics profile' using a combination of omics profiles has revealed several molecular pathways in conditions of health and disease [146]. A further approach is the concept of the 'exposome', which includes all accumulative environmental exposures that, in association with genetic factors, determine the risk of disease [147].

Omics technologies can be used in a number of ways, including testing a single hypothesis, a number of hypotheses, or without any predetermined hypothesis at all; they can also be applied to a small number of individuals. Such technologies produce a vast amount of data, creating the challenge of how to organize data to empower decision-making. How can we transform this 'boom' of knowledge into a dietary recommendation for a patient? Emerging and future recommendations for personalized nutrition are being analyzed (fig. 1).

The extensive yield of genetic knowledge needs to be translated into useful information to be applicable $[148,149]$. Development of new statistical methodologies that can provide integrated, joint evaluation of genotype and environment, using all the omics technologies, and enabling optimum exploration of data, is necessary [124]. Integrating multidimensional data to characterize the nutritional status of individuals as well as their risk of disease, and then customizing an appropriate diet, is a vital part of personalized nutrition [150]. Concurrent with the emergence of new technologies and analysis methods, new companies are emerging to help scientists clarify and organize their results. One such tool is the k-cluster analysis, which subdivides a set of items into similar subgroups or clusters (similar patterns) models [151] and can be used to conglomerate data on genetic polymorphisms and gene expression.

Because nutrigenetics are sciences with enormous potential, it becomes increasingly important for scientists to work with bioinformaticists. The future of genomic sciences depends on the speed and power of new bioinformatics tools [152] and on how such tools will enable health professionals to personalize treatment and diet. Use of these bioinformatic and mathematical tools will be essential to support new nutritional strategies and interventions in public health [153].

The application of personalized nutrition depends on multidisciplinary teams of physicians, geneticists, scientists, bioinformaticists, dietitians, pharmacist and other health professionals, who can analyze genetic profile, integrate all omics analyses and molecular pathways, 
Fig. 2. Translation of nutrigenomics data to dietary advice (population) and nutritional intervention (individual).
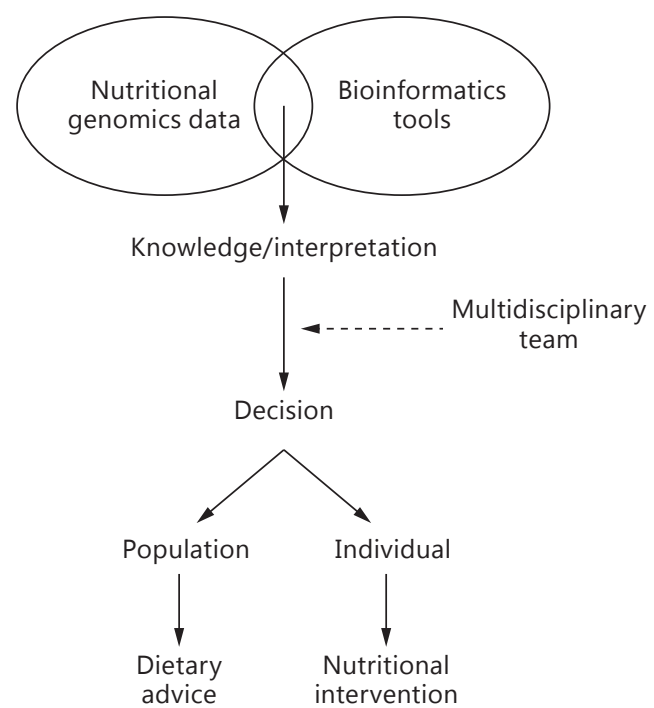

translate knowledge acquired into dietary recommendations and nutritional education, and carry the information gained through to public health policy interventions and strategies (fig. 2).

One barrier to applying genomic technologies in clinical practice is the high cost of genome or exome sequencing [18]. This fact may limit the use of personalized nutrition. Thus, another goal for scientists and industries is to reduce the cost of genetic testing, technologies and products so that they are more affordable for individuals. However, even with a reduction in the cost of genetic testing which is being achieved, it will also be necessary to reduce the cost of advisory services for interpretation of such tests [154].

Privacy and protection of genetic data is another crucial issue. A better understanding of issues relating to ethics and marketing is imperative before personalized nutrition becomes commercially viable for everyone [125]. Future studies need to assess the efficacy of implementation of personalized nutrition [21]. Ultimately, the development of nutrigenetics/ nutrigenomics will bring about new perspectives and progress that will help achieve optimal health of the population [155], with benefits of precision medicine in different health issues [156] including obesity as the most prevalent metabolic disease [44] based on nutrigenetics aspects. Also, the gene-gene interplay and gene-diet interactions should be taken into account for implementation of personalized nutritional interventions and moving towards specific nutrigenetic recommendation algorithms [157-159].

\section{Conclusions}

Public health dietary recommendations are based on the general population. However, with the Human Genome Project and other genetic studies, it is becoming evident that individuals are different in their nutrient requirement and metabolism. Nutrigenomics, including all omics technologies, may assist health professionals in offering personalized advice and customized diets, and may assist in transforming public health recommendations to include 
precision nutrition. These opportunities are opening the door to commercial DTC genetic tests, new food products and technologies, some of which may be suspect. Precision nutrition has a promising future in treating the individual according to their phenotype and genetic characteristics, aimed at both the treatment and prevention of disease. However, many aspects are still in progress and remain as challenges for the future of nutrition. The integration of the human genotype and microbiome needs to be better understood. Further advances in data interpretation tools are also necessary, so that information obtained through tests and technologies can be properly transferred to consumers. Development of new tools such as fluxomics is becoming a part of nutrigenomics/nutrigenetics, enabling advances in bioinformatics analyses. This framework plus reduction in the costs of omics technologies will further the use of these approaches in population studies. An overriding concern remains, however, that ethical and legal regulations are not established and are urgently needed to provide support for the recently coined precision nutrition and medicine terms, to enable universal and personalized applications. Indeed, precision nutrition will integrate genetic data with phenotypical, social, cultural and personal preferences and lifestyles, matters to provide a more individual nutrition but considering public health perspectives.

\section{References}

1 Noecker C, Borenstein E: Getting personal about nutrition. Trends Mol Med 2016;22:83-85.

2 McDonald D, Glusman G, Price ND: Personalized nutrition through big data. Nat Biotechnol 2016;34:152-154.

3 Müller M, Kersten S: Nutrigenomics: goals and strategies. Nat Rev Genet 2003;4:315-322.

4 Trujillo E, Davis C, Milner J: Nutrigenomics, proteomics, metabolomics, and the practice of dietetics. J Am Diet Assoc 2006;106:403-413.

5 Subbiah MT: Understanding the nutrigenomic definitions and concepts at the food-genome junction. OMICS 2008;12:229-235.

6 Miggiano GA, De Sanctis R: Nutritional genomics: toward a personalized diet. Clin Ter 2006;157:355-361.

7 Vakili S, Caudill MA: Personalized nutrition: nutritional genomics as a potential tool for targeted medical nutrition therapy. Nutr Rev 2007;65:301-315.

8 USDA: Dietary Guidelines for Americans 2015-2020, ed 8. 2015. http://healthgov/dietaryguidelines/2015/ guidelines.

9 Habel HJ, Duncavage EJ: Detection of structural DNA variation from next generation sequencing data: a review of informatic approaches. Cancer Genet 2014;206:432e40.

$10 \mathrm{XuJ}$, Wise C, Varma V, Fang H, Ning B, Hong H, et al: Two new ArrayTrack libraries for personalized biomedical research. BMC Bioinformatics 2010;11(suppl 6):S6.

11 Özdemir V, Kolker E: Precision Nutrition 4.0: A Big Data and Ethics Foresight Analysis-Convergene of Agrigenomics, Nutrigenomics, Nutriproteomics and Nutrimetabolomics. Trends Mol Med 2016;20:69-75.

12 Bray MS, Loos RJ, McCaffery JM, Ling C, Franks PW, Weinstock GM, Synder MP, Vassy JL, Agurs-Collins T: NIH working group report-using genomic information to guide weight management: from universal to precision treatment. Obesity 2016;24:14-22.

13 Rubio-Aliaga I, Kochhar S, Silva-Zolezzi I: Biomarkers of nutrient bioactivity and efficacy: a route toward personalized nutrition. J Clin Gastroenterol 2012;46:545-554.

14 Marti A, Goyenechea E, Martinez JA: Nutrigenetics: a tool to provide personalized nutritional therapy to the obese. J Nutrigenet Nutrigenomics 2010;3:157-169.

15 Katsnelson A: Genetics tells tall tales. Nature 2010;465:998.

16 Imai K, Kricka LJ, Fortina P: Concordance study of 3 direct-to-consumer genetic-testing services. Clin Chem 2011;57:518-521.

17 Nielsen DE, Shih S, El-Sohemy A: Perceptions of genetic testing for personalized nutrition: a randomized trial of DNA-based dietary advice. J Nutrigenet Nutrigenomics 2014;7:94-104.

18 Goldenberg AG, Marshall PA, Sharp RR: Next-generation disadvantages: identifying potential barriers to integrating genomics into underserved medical settings. Pers Med 2013;10:623-625.

19 Bragazzi NL: Situating nutri-ethics at the junction of nutrigenomics and nutriproteomics in postgenomics medicine. Curr Pharmacogenomics Person Med 2013;11:162-166.

20 San-Cristobal R, Milagro FI, Martinez JA: Future challenges and present ethical considerations in the use of personalized nutrition based on genetic advice. J Acad Nutr Diet 2013;113:1447-1454.

21 Fallaize R, Macready AL, Butler LT, Ellis JA, Lovegrove JA: An insight into the public acceptance of nutrigenomic-based personalised nutrition. Nutr Res Rev 2013;26:39-48. 


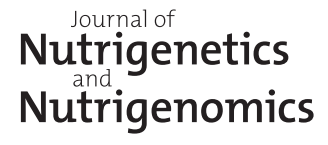

\begin{tabular}{l|l}
\hline J Nutrigenet Nutrigenomics 2016;9:28-46 \\
\hline DOI: 10.1159/000446347 & $\begin{array}{l}\text { c 2016 S. Karger AG, Basel } \\
\text { www.karger.com/jnn }\end{array}$ \\
\hline
\end{tabular}

Kohlmeier et al.: Guide and Position of the ISNN on Personalized Nutrition: Part 2 Ethics, Challenges and Endeavors of Precision Nutrition

22 Nielsen DE, El-Sohemy A: Disclosure of genetic information and change in dietary intake: a randomized controlled trial. PLoS One 2014;9:e112665.

23 Arkadianos I, Valdes AM, Marinos E, Florou A, Gill RD, Grimaldi KA: Improved weight management using genetic information to personalize a calorie controlled diet. Nutr J 2007;6:29.

24 Joost HG, Gibney MJ, Cashman KD, Gorman U, Hesketh JE, Mueller M, et al: Personalised nutrition: status and perspectives. Br J Nutr 2007;98:26-31.

25 Food4Me. http://www.food4me.org.

26 Kussmann M, Fay LB: Nutrigenomics and personalized nutrition: science and concept. Pers Med 2008;5:447455.

27 Fay LB, German JB: Personalizing foods: is genotype necessary? Curr Opin Biotechnol 2008;19:121-128.

28 Neeha VS, Kinth P: Nutrigenomics research: a review. J Food Sci Technol 2013;50:415-428.

29 Gillies PJ: Nutrigenomics: the Rubicon of molecular nutrition. J Am Diet Assoc 2003;103(suppl 2):S50-S55.

30 Ferguson LR: Foods and personalized nutrition; in Ferguson LR (ed): Nutrigenomics and Nutrigenetics in Functional Foods and Personalized Nutrition. Boca Raton, CRC Press, 2014, pp 3-23.

31 Mariman EC: Nutrigenomics and nutrigenetics: the 'omics' revolution in nutritional science. Biotechnol Appl Biochem 2006;44:119-128.

32 Ronteltap A, van Trijp H, Berezowska A, Goossens J: Nutrigenomics-based personalised nutritional advice: in search of a business model? Genes Nutr 2013;8:153-163.

33 Kohlmeier M: Pratical uses of nutrigenetics; in Kolhmeier M (ed): Nutrigenetics: Applying the Science of Personalized Nutrition. Amsterdam, Elsevier, 2013, pp 307-333.

34 http://www.nutrigen.com.

35 Technology Assisted Dietary Assessment. http://www.tadaproject.org.

36 Zhu F, Bosch M, Woo I, Kim S, Boushey CJ, Ebert DS, et al: The Use of Mobile Devices in Aiding Dietary Assessment and Evaluation. IEEE J Sel Top Signal Process 2010;4:756-766.

37 Kerr DA, Pollard CM, Howat P, Delp EJ, Pickering M, Kerr KR, et al: Connecting Health and Technology (CHAT): protocol of a randomized controlled trial to improve nutrition behaviours using mobile devices and tailored text messaging in young adults. BMC Public Health 2012;12:477.

38 Bergmann MM, Gorman U, Mathers JC: Bioethical considerations for human nutrigenomics. Annu Rev Nutr 2008;28:447-467.

39 Mensink RP, Plat J: Post-genomic opportunities for understanding nutrition: the nutritionist's perspective. Proc Nutr Soc 2002;61:401-404.

40 Sempos CT, Liu K, Ernst ND: Food and nutrient exposures: what to consider when evaluating epidemiologic evidence. Am J Clin Nutr 1999;69:1330S-1338S.

41 El-Sohemy A: Nutrigenetics. Forum Nutr 2007;60:25-30.

42 Gibney MJ, Gibney ER: Diet, genes and disease: implications for nutrition policy. Proc Nutr Soc 2004;63:491500.

43 Stover PJ: Influence of human genetic variation on nutritional requirements. Am J Clin Nutr 2006;83:436S442S.

44 Alfredo Martínez J: Perspectives on personalized nutrition for obesity. J Nutrigenet Nutrigenomics 2014; 7:I-III.

45 Suh JR, Herbig AK, Stover PJ: New perspectives on folate catabolism. Annu Rev Nutr 2001;21:255-282.

46 Bailey LB, Gregory JF 3rd: Polymorphisms of methylenetetrahydrofolate reductase and other enzymes: metabolic significance, risks and impact on folate requirement. J Nutr 1999;129:919-922.

47 Marreiro Ddo N, de Sousa AF, Nogueira Ndo N, Oliveira FE: Effect of zinc supplementation on thyroid hormone metabolism of adolescents with Down syndrome. Biol Trace Elem Res 2009;129:20-27.

48 Pogribna M, Melnyk S, Pogribny I, Chango A, Yi P, James SJ: Homocysteine metabolism in children with Down syndrome: in vitro modulation. Am J Hum Genet 2001;69:88-95.

49 Ordovas JM, Mooser V: Nutrigenomics and nutrigenetics. Curr Opin Lipidol 2004;15:101-108.

50 Rao AD, Sun B, Saxena A, Hopkins PN, Jeunemaitre X, Brown NJ, et al: Polymorphisms in the serum- and glucocorticoid-inducible kinase 1 gene are associated with blood pressure and renin response to dietary salt intake. J Hum Hypertens 2013;27:176-180.

51 Wooding S: Natural selection: sign, sign, everywhere a sign. Curr Biol 2004;14:R700-R701.

52 Akey JM, Eberle MA, Rieder MJ, Carlson CS, Shriver MD, Nickerson DA, et al: Population history and natural selection shape patterns of genetic variation in 132 genes. PLoS Biol 2004; 2:e286.

53 Mustalahti K, Catassi C, Reunanen A, Fabiani E, Heier M, McMillan S, et al: The prevalence of celiac disease in Europe: results of a centralized, international mass screening project. Ann Med 2010;42:587-595.

54 Simopoulos AP: Genetic variation and dietary response: nutrigenetics and nutrigenomics. Asia Pacific J Clin Nutr 2002;1(suppl 6):S117-S128.

55 Sibley E: Genetic variation and lactose intolerance: detection methods and clinical implications. Am J Pharmacogenomics 2004;4:239-245.

56 Marchlewicz EH, Peterson KE, Omenn GS: Public health context for nutrigenomics and personalized nutrition; in Ferguson LR (ed): Nutrigenomics and Nutrigenetics in Functional Foods and Personalized Nutrition. Boca Raton, CRC Press, 2014, pp 375-397.

57 Fenech M, El-Sohemy A, Cahill L, Ferguson LR, French TA, Tai ES, et al: Nutrigenetics and nutrigenomics: viewpoints on the current status and applications in nutrition research and practice. J Nutrigenet Nutrigenomics 2011;4:69-89. 
58 Stover PJ: Nutritional genomics. Physiol Genomics 2004;16:161-165.

59 Cambon-Thomsen A, Rial-Sebbag E, Knoppers BM: Trends in ethical and legal frameworks for the use of human biobanks. Eur Respir J 2007;30:373-382.

60 Niculescu MD: Are We Ready for Personalized Dietary Guidelines? J Hum Nutr Food Sci 2013;1:1013.

61 Camp KM, Trujillo E: Position of the Academy of Nutrition and Dietetics: nutritional genomics. J Acad Nutr Diet 2014;114:299-312.

62 Castle D, Ries NM: Ethical, legal and social issues in nutrigenomics: the challenges of regulating service delivery and building health professional capacity. Mutat Res 2007;622:138-143.

63 Ronteltap A, Van Trijp JCM, Renes RJ: Consumer acceptance of nutrigenomics-based personalised nutrition. Br J Nutr 2009;101:132-144.

64 Sjöberg L: Gene technology in the eyes of the public and experts. Moral opinions, attitudes and risk perception. SSE/EFI - Working Paper Series in Business Administration 2004;7.

65 Stewart-Knox BJ, Bunting BP, Gilpin S, Parr HJ, Pinhao S, Strain JJ, et al: Attitudes toward genetic testing and personalised nutrition in a representative sample of European consumers. Br J Nutr 2009;101:982-989.

66 Roosen J, Bruhn M, Mecking RA, Drescher LS: Consumer demand for personalized nutrition and functional food. Int J Vitam Nutr Res 2008;78:269-274.

67 Ahlgren J, Nordgren A, Perrudin M, Ronteltap A, Savigny J, van Trijp H, et al: Consumers on the Internet: ethical and legal aspects of commercialization of personalized nutrition. Genes Nutr 2013;8:349-355.

68 Catz DS, Green NS, Tobin JN, Lloyd-Puryear MA, Kyler P, Umemoto A, et al: Attitudes about genetics in underserved, culturally diverse populations. Community Genet 2005;8:161-172.

69 Costa-Font J, Mossialos E: Are perceptions of 'risk' and 'benefits' of genetically modified food (in)dependent? Food Qual Prefer 2007;18:173-182.

70 Nielsen DE, El-Sohemy A: A randomized trial of genetic information for personalized nutrition. Genes Nutr 2012; 7:559-566.

71 Bloss CS, Schork NJ, Topol EJ: Effect of direct-to-consumer genome wide profiling to assess disease risk. N Engl J Med 2011;364:524-534.

72 Council of Europe: Additional Protocol to the Convention on Human Rights and Biomedicine, concerning Genetic Testing for Health Purposes (Strasbourg). Eur J Health Law 2008;15:441-450.

73 Khoury MJ, Gwinn M, Bowen MS, Dotson WD: Beyond base pairs to bedside: a population perspective on how genomics can improve health. Am J Public Health 2012;102:34-37.

74 Arab L: Individualized nutritional recommendations: do we have the measurements needed to assess risk and make dietary recommendations? Proc Nutr Soc 2004;63:167-172.

75 McCarthy S, Pufulete M, Whelan K: Factors associated with knowledge of genetics and nutritional genomics among dietitians. J Hum Nutr Diet 2008;21:547-554.

76 Prasad C, Imrhan V, Rew M: Introducing nutritional genomics teaching in under-graduated dietetic curricula. J Nutrigenet Nutrigenomics 2011;4:165-172.

77 Roche PA, Annas GJ: Protecting genetic privacy. Nat Rev Genet 2001;2:392-396.

78 European Commission: The 25 recommendations on ethical, legal and social implications of genetic testing. Luxembourg, Office for Official Publications of the European Communities, 2004.

79 Caulfield T, McGuire AL: Direct-to-consumer genetic testing: perceptions, problems, and policy responses. Annu Rev Med 2012;63:23-33.

80 Kohlmeier M: Keeping genetic information safe; in Kohlmeier M (ed): Nutrigenetics Applying the Science of Personal Nutrition. Amsterdam, Elsevier, 2013, pp 335-353.

81 Wertz D, Fletcher J, Berg K: Review of Ethical Issues in Medical Genetics. Report of Consultants to WHO. Geneva, WHO, 2003.

82 Grimaldi KA, Look MP, Scioli GA, Clavero JC, Marinos S, Tagaris T: Personal genetics: regulatory framework in Europe from a service provider's perspective. Eur J Hum Genet 2011;19:382-388.

83 Hogarth S: Regulation of genetic tests: an international comparison; in Castle D, Ries NM (ed): Nutrition and Genomics: Issues of Ethics, Law, Regulation and Communication. Amsterdam, Elsevier, 2009, pp 63-83.

84 The NuGO Bioethics Guidelines on Human Studies. Oslo, September 17, 2007. http://nugo.dife.de/bot/index. php.

85 Yuji K, Tanimoto T, Oshima Y: 23andMe and the FDA. N Engl J Med 2014;370:2248.

86 Federal Trade Commission: FTC Facts for Consumer. At-Home Genetic Test: A Healthy Dose of Skepticism May Be the Best Prescription. Washington, Federal Trade Commission, 2006.

87 Human Genetic Commission (UK HGC): A Common Framework of Principles for Direct-to-Consumer Genetic Testing Services. London, Human Genome Commission, 2010.

88 US Government Accountability Office: Nutrigenetic Testing: Tests Purchased from Four Web Sites Mislead Consumers. 2006. www.gao/gov/new.items/d06977t.pdf.

89 Nuffield Council of Bioethics: Medical Profiling and Online Medicine: The Ethics of Personalized Healthcare in a Consumer Age. London, Nuffield Press, 2010.

90 http://www.genome.gov/19016590.

91 Collins FS, Hamburg MA: First FDA authorization for next-generation sequencer. N Engl J Med 2013;369: 2369-2371.

92 http://www.genome.gov/10002335.

93 Evans JP: Query regarding FDA regulation of genetic testing. Email communication. 2015. 
94 The German Human Genetic Examination Act (Gesetz über genetische Untersuchungen bei Menschen Gendiagnostikgesetz-GenDG). 2009.

95 Superior Health Council: Publication of the Superior Health Council No. 8714. Brussels, Superior Health Council, 2012.

96 Borry P, van Hellemondt RE, Sprumont D, Jales CF, Rial-Sebbag E, Spranger TM, et al: Legislation on direct-toconsumer genetic testing in seven European countries. Eur J Hum Genet 2012;20:715-721.

97 Gibney MJ, Walsh M: Deliverable 6.22. Personalised nutrition: an integrated analysis of opportunities and challenges - white paper by Food4Me partners. Theme KBBE. 2010.2.3-02. March 2015.

98 The regulation of nutrigenetic test in Australia. https://www.tga.gov.au/regulation-nutrigenetic-testsaustralia.

99 Vayena E: Direct-to-consumer genomics on the scales of autonomy. J Med Ethics 2015;41:310-314.

100 http://www.fda.gov/iceci/enforcementactions/warningletters/2013/ucm376296.htm.

101 Baudhuin LM: The FDA and 23andMe: violating the First Amendment or protecting the rights of consumers? Clin Chem 2014;60:835-837.

102 Zettler PJ, Sherkow JS, Greely HT: 23andMe, the Food and Drug Administration, and the future of genetic testing. JAMA Intern Med 2014;174:493-494.

103 Annas GJ, Elias S: 23andMe and the FDA. N Engl J Med 2014;370:985-988.

104 Annas GJ, Elias S: 23andMe and the FDA. N Engl J Med 2014;370:2248-2249.

105 Nordstrom K, Coff C, Jonsson H, Nordenfeldt L, Gorman U, Food4Me: Food and health: individual, cultural, or scientific matters? Genes Nutr 2013;8:357-363.

106 Gorman U: Ethical issues raised by personalized nutrition based on genetic information. Genes Nutr 2006;1: $13-22$.

107 Lu Y, Tayebi N, Li H, Saha N, Yang H, Heng CK: Association of CETP Taq1B and -629C > A polymorphisms with coronary artery disease and lipid levels in the multi-ethnic Singaporean population. Lipids Health Dis 2013; 12:85.

108 Huang D, Xie X, Ma YT, Huang Y, Ma X: Endothelial lipase-384A/C polymorphism is associated with acute coronary syndrome and lipid status in elderly Uygur patients in Xinjiang. Genet Test Mol Biomarkers 2014; 18:781-784.

109 Kaput J: Nutrigenomics research for personalized nutrition and medicine. Curr Opin Biotechnol 2008;19: 110-120.

110 Ganesh V, Hettiarachchy NS: Nutriproteomics: a promising tool to link diet and diseases in nutritional research. Biochim Biophys Acta 2012;1824:1107-1117.

111 Kussmann M, Krause L, Siffert W: Nutrigenomics: where are we with genetic and epigenetic markers for disposition and susceptibility? Nutr Rev 2010;68(suppl 1):S38-S47.

112 Panagiotou G, Nielsen J: Nutritional systems biology: definitions and approaches. Annu Rev Nutr 2009;29: 329-339.

113 Tucker KL, Smith CE, Lai CQ, Ordovas JM: Quantifying diet for nutrigenomic studies. Annu Rev Nutr 2013;33: 349-371.

114 German JB, Zivkovic AM, Dallas DC, Smilowitz JT: Nutrigenomics and personalized diets: what will they mean for food? Annu Rev Food Sci Technol 2011;2:97-123.

115 Pers TH, Timshel P, Hirschhorn JN: SNPsnap: a Web-based tool for identification and annotation of matched SNPs. Bioinformatics 2015;31:418-420.

116 Zadak Z, Ticha A, Hronek M, Hyspler R: Advances in metabolism and nutrition 2011 and the route to personalized treatment. Vnitr Lek 2011;57:970-974.

117 Gibney MJ, McNulty BA, Ryan MF, Walsh MC: Nutritional phenotype databases and integrated nutrition: from molecules to populations. Adv Nutr 2014;5:352S-357S.

118 Baturin AK, Sorokina E, Pogozheva AV, Tutel'ian VA: Genetic approaches to nutrition personalization. Vopr Pitan 2012;81:4-11.

119 Kamleh MA, Spagou K, Want EJ: Metabolic profiling in disease diagnosis, toxicology and personalized healthcare. Curr Pharm Biotechnol 2011;12:976-995.

120 Kang JX: Identification of metabolic biomarkers for personalized nutrition. J Nutrigenet Nutrigenomics 2012;5:I-II.

121 Rauschert S, Uhl O, Koletzko B, Hellmuth C: Metabolomic biomarkers for obesity in humans: a short review. Ann Nutr Metab 2014;64:314-324.

122 Wang P, Holst C, Astrup A, Bouwman FG, van Otterdijk S, Wodzig WK, et al: Blood profiling of proteins and steroids during weight maintenance with manipulation of dietary protein level and glycaemic index. Br J Nutr 2012;107:106-119.

123 Wang P, Holst C, Wodzig WK, Andersen MR, Astrup A, van Baak MA, et al: Circulating ACE is a predictor of weight loss maintenance not only in overweight and obese women, but also in men. Int J Obes (Lond) 2012; 36:1545-1551.

124 Ong ML, Lin X, Holbrook JD: Measuring epigenetics as the mediator of gene/environment interactions in DOHaD. J Dev Orig Health Dis 2015;6:10-16.

125 de Roos B: Personalised nutrition: ready for practice? Proc Nutr Soc 2013;72:48-52.

126 Kang JX: Gut microbiota and personalized nutrition. J Nutrigenet Nutrigenomics 2013;6:I-II.

127 Dutton RJ, Turnbaugh PJ: Taking a metagenomic view of human nutrition. Curr Opin Clin Nutr Metab Care 2012;15:448-454. 
128 Bjorksten B, Sepp E, Julge K, Voor T, Mikelsaar M: Allergy development and the intestinal microflora during the first year of life. J Allergy Clin Immunol 2001;108:516-520.

129 Hyotylainen T, Bondia-Pons I, Oresic M: Lipidomics in nutrition and food research. Mol Nutr Food Res 2013; 57:1306-1318.

130 Claus SP, Swann JR: Nutrimetabonomics: applications for nutritional sciences, with specific reference to gut microbial interactions. Annu Rev Food Sci Technol 2013;4:381-399.

131 Watkins SM, Hammock BD, Newman JW, German JB: Individual metabolism should guide agriculture toward foods for improved health and nutrition. Am J Clin Nutr 2001;74:283-286.

132 Beckmann M, Lloyd AJ, Haldar S, Fave G, Seal CJ, Brandt K, et al: Dietary exposure biomarker-lead discovery based on metabolomics analysis of urine samples. Proc Nutr Soc 2013;72:352-361.

133 Merched AJ, Chan L: Nutrigenetics and nutrigenomics of atherosclerosis. Curr Atheroscler Rep 2013;15:328.

134 Juma S, Imrhan V, Vijayagopal P, Prasad C: Prescribing personalized nutrition for cardiovascular health: are we ready? J Nutrigenet Nutrigenomics 2014;7:153-160.

135 Martínez JA: Perspectives on personalized nutrition for obesity. J Nutrigenet Nutrigenomics 2014;7;I-III.

136 Qi L, Cho YA: Gene-environment interaction and obesity. Nutr Rev 2008;66:684-694.

137 Engler MB: Nutrigenomics in cardiovascular disease: implications for the future. Prog Cardiovasc Nurs 2009; 24:190-195.

138 Martinez JA, Navas-Carretero S, Saris WH, Astrup A: Personalized weight loss strategies - the role of macronutrient distribution. Nat Rev Endocrinol 2014;10:749-760.

139 Stewart-Knox B, Kuznesof S, Robinson J, Rankin A, Orr K, Duffy M, et al: Factors influencing European consumer uptake of personalised nutrition. Results of a qualitative analysis. Appetite 2013;66:67-74.

140 Brug J, Campbell M, van Assema P: The application and impact of computer-generated personalized nutrition education: a review of the literature. Patient Educ Couns 1999;36:145-156.

141 Nordstrom K, Juth N, Kjellstrom S, Meijboom FL, Gorman U, Food4Me project: Values at stake: autonomy, responsibility, and trustworthiness in relation to genetic testing and personalized nutrition advice. Genes Nutr 2013;8:365-372.

142 Eguilaz MHR, Milagro FI, San-Cristobal R, Cuervo M, Ibáñez A, Martinez JA: Nutrigenética: una nueva oportunidad para la oficina de farmacia. El Farmaceutico 2014;499:12-24.

143 Cormier H, Tremblay BL, Paradis AM, Garneau V, Desroches S, Robitaille J, et al: Nutrigenomics - perspectives from registered dietitians: a report from the Quebec-wide e-consultation on nutrigenomics among registered dietitians. J Hum Nutr Diet 2014;27:391-400.

144 Lovegrove JA, Gitau R: Nutrigenetics and CVD: what does the future hold? Proc Nutr Soc 2008;67:206.

145 Cornelis MC, Hu FB: Systems epidemiology: a new direction in nutrition and metabolic disease research. Curr Nutr Rep 2013;2.

146 Chen R, Mias GI, Li-Pook-Than J, Jiang L, Lam HY, Chen R, et al: Personal omics profiling reveals dynamic molecular and medical phenotypes. Cell 2012;148:1293-1307.

147 Wild CP: Complementing the genome with an 'exposome': the outstanding challenge of environmental exposure measurement in molecular epidemiology. Cancer Epidemiol Biomarkers Prev 2005;14:1847-1850.

148 Phillips CM: Nutrigenetics and metabolic disease: current status and implications for personalised nutrition. Nutrients 2013;5:32-57.

149 Lundstrom K: Past, present and future of nutrigenomics and its influence on drug development. Curr Drug Discov Technol 2013;10:35-46.

150 Lampe JW, Navarro SL, Hullar MA, Shojaie A: Inter-individual differences in response to dietary intervention: integrating omics platforms towards personalised dietary recommendations. Proc Nutr Soc 2013;72:207218.

151 D'Haeseleer P: How does gene expression clustering work? Nat Biotechnol 2005;23:1499-1501.

152 Sheldon J, Ou W: The real informatics challenges of personalized medicine: not just about the number of central processing units. Pers Med 2013;10:639-645.

153 Rimbach G, Minihane AM: Nutrigenetics and personalised nutrition: how far have we progressed and are we likely to get there? Proc Nutr Soc 2009;68:162-172.

154 Brunham LR, Hayden MR: Medicine. Whole-genome sequencing: the new standard of care? Science 2012;336: 1112-1113.

155 Ghosh D: Future perspectives of nutrigenomics foods: benefits vs risks. Indian J Biochem Biophys 2009;46: 31-36.

156 Bahcall 0: Precision medicine. Nature 2015;526:335.

157 Goni L, Cuervo M, Milagro FI, Martínez JA: Gene-gene interplay and gene-diet interactions involving the MTNR1B rs10830963 variant with body weight loss. J Nutrigenet Nutrigenomics 2014;7:232-242.

158 Goni L, Cuervo M, Milagro FI, Martínez JA: Future perspectives of personalized weight loss intervention based on nutrigenetic, epigenetic and metagenomic data. J Nutr 2016;146:905S-912S.

159 De Caterina R, El-Sohemy A: Moving towards specific nutrigenetic recommendation algorithms. Caffeine, genetic variation and cardiovascular Risk. J Nutrigenet Nutrigenomics 2016, in press. 